\title{
Medicalização dos Modos de Ser e de Aprender
}

\author{
Ana Carolina Christofari' \\ Claudia Rodrigues de Freitas \\ Claudio Roberto Baptista'
}

'Universidade Federal do Rio Grande do Sul (UFRGS), Porto Alegre/RS-Brasil

RESUMO - Medicalização dos Modos de Ser e de Aprender. Este artigo analisa os modos de ser e aprender na escola, considerando a medicalização como dispositivo que transforma comportamentos da vida humana em patologias. Investe-se na dimensão histórico-conceitual, problematizando esse processo. Os acontecimentos escolares apresentados dão visibilidade à prática escolar de inventar diagnósticos que justifiquem o não-aprender. $\mathrm{O}$ presente artigo apoia-se no pensamento foucaultiano, sobretudo, em relação à estratégia constitutiva de subjetividades pelos discursos. A análise, ao problematizar as práticas escolares e os discursos patologizantes, investe na compreensão da condição humana considerada em permanente transformação.

Palavras-chave: Educação Especial. Medicalização. Patologização. Inclusão Escolar.

ABSTRACT - Medicalization of Modes of Being and Learning. This article analyzes the modes of being and learning in school, considering medicalization as a device that transforms human life behaviors in pathologies. We invest in the historical-conceptual dimension, discussing this process. The school events here presented provide visibility to the practice of inventing diagnoses that justify the non-learning. The article is built on Foucault's thinking, particularly in relation to the strategy of subjectivity constitution by discourse. The analysis focuses on the comprehension of the everchanging human condition, while it discusses school practices and pathologizing discourses.

Keywords: Special Education. Medicalization. Pathologization. School Inclusion.

Educação \& Realidade, Porto Alegre, v. 40, n. 4, p. 1079-1102, out./dez. 2015.1079 http://dx.doi.org/10.1590/2175-623642057 
Medicalização dos Modos de Ser e de Aprender

$$
\begin{array}{r}
\text { Quando nasci veio um anjo safado } \\
\text { O chato do querubim } \\
\text { E decretou que eu estava predestinado } \\
\text { A ser errado assim } \\
\text { Já de saída a minha estrada entortou } \\
\text { Mas vou até o fim } \\
\text { “inda" garoto deixei de ir à escola } \\
\text { Cassaram meu boletim } \\
\text { Não sou ladrão, eu não sou bom de bola } \\
\text { Nem posso ouvir clarim } \\
\text { Um bom futuro é o que jamais me esperou } \\
\text { Mas vou até o fim }{ }^{1}
\end{array}
$$

Irrequietos. Desatentos. Preguiçosos. Características individuais ou patologias? Discutir e analisar o processo de patologização dos modos de ser e de aprender, no ambiente escolar, é a aspiração deste artigo. Ao dar ênfase à patologização, são colocados em destaque os aspectos que tendem a configurar as condições de aprendizagem e suas impossibilidades como parte constitutiva do processo de medicalização.

A diversidade humana tem sido diariamente produzida por um amplo processo de medicalização, atribuindo aos indivíduos uma série de rótulos e classificações, os inserindo em uma rede de explicações patológicas. Medicalização é um dispositivo que transforma problemas políticos, sociais e culturais em questões pessoais a serem tratadas ou medicadas. Isola-se o indivíduo de um contexto para analisar em detalhe suas particularidades e torná-las patológicas. Produz-se um modo de olhar para o outro como se ele fosse uma simples somatória de características biológicas e comportamentais, ambas tomadas como ponto de partida para a definição da presença de possíveis patologias.

As questões biológicas referem-se, na maioria dos casos, à genética, à hereditariedade que foi o ponto de partida para a teoria da degenerescência. Esta foi desenvolvida sobre o modo como a espécie humana tende a se deteriorar. A ideia de uma espécie de contaminação, transmissão dos males e desvios humanos, foi se desenvolvendo com base na atribuição de um caráter de cientificidade para explicar porque alguns sujeitos representam, em seu corpo e sua conduta, a transgressão às leis humanas e às leis naturais. No Traité des dégénéscences (Tratado das degenerescências), de 1857, Morel define uma modificação no organismo de um tipo primitivo perfeito:

Esse desvio, por mais simples que seja suposto em sua origem, encerra, no entanto, elementos de transmissibilidade de tal natureza que aquele que carrega seu germe torna-se cada vez mais incapaz de cumprir sua função na humanidade, e que o progresso intelectual já bloqueado em sua pessoa encontra-se ainda ameaçado na de seus descendentes (Morel, 2008, p. 500).

Essa transformação seria um desvio mórbido que poderia causar danos ao desenvolvimento da espécie humana. A teoria alinha-se a um

1080 Educação \& Realidade, Porto Alegre, v. 40, n. 4, p. 1079-1102, out./dez. 2015. 
caráter moralizante, pois as principais causas da degenerescência seriam os desvios de inteligência e de conduta em relação às regras socialmente estabelecidas. A imoralidade dos costumes, a intoxicação, enfermidades congênitas, relações consideradas promíscuas, eram algumas das ações que causariam danos ao organismo e poderiam ser transmitidas às gerações descendentes, produzindo uma linhagem atingida e constituída como inferior. A ideia de uma predisposição hereditária ou adquirida cria uma condição de sujeito fragilizado. Este sujeito, por estar em contato com uma situação capaz de colocar sua integridade física e moral em perigo, teria uma maior probabilidade de desenvolver alguma patologia.

As questões comportamentais, ou os chamados desvios de conduta, tornam-se sintomas patológicos na medida em que a racionalidade médica, sobretudo o discurso médico-clínico, se faz presente em todos os campos da vida e se expande pelas diferentes práticas educativas. Nas primeiras décadas do Século XX, com a intensificação das práticas higienistas no Brasil e com a inserção destas na escola, atua-se de modo a prevenir maus hábitos. Para tanto, a manutenção da saúde seria possível por meio do cuidado dirigido às condições de vida, às relações sociais entre adultos e crianças, às relações familiares. Nesse sentido, a família passa a ser compreendida como forte influência sobre o desenvolvimento de cada criança, sobretudo em relação ao desenvolvimento escolar, tanto como transmissora de genes supostamente saudáveis, frágeis, doentes, como produtora de condutas que poderiam justificar a julgada incapacidade do indivíduo de se adaptar às condições sociais nas quais está inserido.

Ao analisar a participação de Arthur Ramos², inscrita na década de 1930 na educação brasileira, e o modo como se foi construindo a ideia de uma criança anormal, a qual ele passa a denominar criança problema. Silva (2011) afirma que diversas situações podem gerar a inadequação social da criança e analisa os casos apresentados por Ramos em seu livro intitulado A Criança Problema, publicado em 1939. Considerando esses casos, ficou perceptível que nas fichas de atendimentos no serviço de ortofrenia e higiene mental em escolas públicas experimentais do Distrito Federal,

[...] constavam anotações sobre o sexo e a idade da criança, a profissão dos pais, indicando se eram vivos e se dispunham de boa saúde, em que circunstâncias se deram a gestação e o parto, se tinha irmãos e/ou outros familiares morando na mesma casa, quais as condições de habitação, informações sobre as atividades desenvolvidas durante o dia, as alterações do sono, seus medos e aspectos da personalidade. Em sequência, apresentavam os hábitos e as queixas escolares e se havia problemas orgânicos (Silva, 2011, p. 62).

Para o campo da educação, a relação família e comportamentos considerados inadequados, ou mesmo a suposta incapacidade cogniti-

Educação \& Realidade, Porto Alegre, v. 40, n. 4, p. 1079-1102, out./dez. 2015.1081 
va, sempre formaram um elo importante de constituição dos discursos sobre os alunos considerados fora dos padrões de aluno ideal. Até hoje, tais discursos justificam a suposta não-aprendizagem de muitos alunos, baseados na concepção de uma espécie de herança familiar dos males genéticos e de conduta.

No ambiente escolar o processo de medicalização pode ser definido como práticas que indicariam quais alunos estariam aptos a permanecer na escola e a aprender na forma determinada por esta instituição. A medicalização é a produção social de doenças que justificam a suposta não-aprendizagem de uma ampla gama de alunos, os quais não se enquadram no perfil de aluno padrão. Este modo de subjetivação nos convoca a problematizar a classificação da diversidade humana como desvio, distúrbio, como patologia. Nesse sentido analisaremos a emergência daquilo que estamos chamando de medicalização e a forma através da qual esse processo se faz visível nas práticas escolares, a partir da compreensão de que os discursos são parte das práticas de medicalização.

A letra da música de Chico Buarque, evocada na epígrafe, nos dá pistas de como esse processo tem se tornado potente na constituição de lugares de sujeito, pois apresenta uma vida que resiste ao que lhe foi predestinada: uma vida produzida como obra de arte, porque não se deixa capturar pelas previsões e luta para escapar do caminho aparentemente inexorável. Podemos encontrar muitas dessas vidas na escola. Em um contínuo jogo de resistência e luta para ingressar no universo daqueles que sabem, aprendem, algumas vezes tais sujeitos entram em confronto com práticas que tendem a tornar um determinado modo de ser e estar, na vida, patológico. Diz o personagem da música: "Predestinado a ser errado" e "inda" garoto deixei de ir à escola. Nas linhas dessa música vimos uma vida construída, como errante, desde o nascimento, mas relutante, em litígio constante, se negando a ocupar o lugar que lhe é proposto. O movimento de luta torna visível a tentativa de evitar um processo que, em função da evocação do lugar da escola - "Cassaram meu boletim" -, poderia ser aproximado do que, no âmbito do presente texto, é designado como processo de medicalização. Apesar da tentativa de escapar das rotulações, das nomeações, dos diagnósticos que desenham um quadro estático das potencialidades de cada sujeito, todos nós somos de alguma maneira, em diferentes momentos de nossas vidas, compostos por uma racionalidade que governa as condutas e os modos de ser. Essa racionalidade pode, ao considerarmos os desvios e as condutas, ser identificada como racionalidade médica. "A medicina é um saber-poder que incide ao mesmo tempo sobre o corpo e sobre a população, sobre o organismo e sobre os processos biológicos e vai, portanto, ter efeitos disciplinares e efeitos regulamentadores" (Foucault, 2010b, p. 212). A medicalização torna-se um dispositivo de gestão de controle dos corpos.

1082 Educação \& Realidade, Porto Alegre, v. 40, n. 4, p. 1079-1102, out./dez. 2015. 


\section{Medicalização: historiando um dispositivo}

A medicalização ${ }^{3}$ é um processo de produção de lugares, um dispositivo funcionando em forma de rede disposta em um conjunto rizomático, "[...] heterogêneo que engloba discursos, instituições, organizações arquitetônicas, decisões regulamentares, leis, medidas administrativas, enunciados científicos, proposições filosóficas, morais, filantrópicas..." de forma que "o dito e o não dito são os elementos do dispositivo". O dispositivo "[...] é a rede que se pode estabelecer entre estes elementos" (Foucault, 2011, p. 244). São disposições, produzindo subjetividades, movimentando linhas de saber constituídas de discursos científicos. No dispositivo da medicalização, uma das máquinas concretas é a escola: ela cria lugares de sujeito, regimes de luz e enunciados que colocam em funcionamento e atualizam o processo da medicalização dos modos de ser e de aprender. Essa maquinaria dispõe visibilidades e enunciados, colocando o indivíduo no papel de anormal; é isso que faz o dispositivo da medicalização: cria lugares para cada um ocupar. Diante desse processo, os modos de ser e as condutas são diagnosticados, classificados e inseridos em um amplo universo nosográfi$\mathrm{CO}^{4}$.

A terminologia Medicalização da vida foi inicialmente utilizada por Ivan Illich ${ }^{5}$, em seu livro A Expropriação da Saúde (1975) para descrever a inserção crescente dos saberes médicos, e seu aparato denominado de progresso científico (Illich, 1975), em campos da vida individual que passam a ser submetidos a explicações e intervenções médicas. Ivan Illich discute como uma mentalidade médica vai se alastrando e influenciando todas as relações sociais; esse processo ele chama de medicalização da vida. Ao longo de sua obra, descreve alguns dos sintomas sociais definidos como sendo consequências do processo de medicalização da vida. Illich interpreta esses sintomas como males típicos de uma civilização superindustrializada e, ainda, afirma que essa ampla intervenção médica na vida cotidiana acaba por causar muitos prejuízos à sociedade, sendo um deles o que o autor chama de iatrogênese (iatros - médico; genesis - origem). Esse termo refere-se à epidemia de enfermidades produzidas pela intervenção médica. Enfermidades que não teriam aparecido se não houvesse aplicação de tratamentos recomendados pelos médicos. Trata-se de um processo complexo de ser identificado, mas que evoca a circularidade produtora que congrega o ato de cuidar, o uso dos instrumentos do cuidado - medicação ou palavra - e a produção de novas fragilidades associadas ao adoecimento, como a resistência corporal a determinados tratamentos ou a identificação patológica em determinadas práticas sociais. A partir dessa postura crítica, Illich define a polaridade: medicina e antimedicina.

Foucault (2010a) se distancia desta dicotomia e das ideias de Illich ao propor que se pense em outra direção, buscando compreender "[...] em que se consistiu a 'decolagem' sanitária e médica das sociedades de

Educação \& Realidade, Porto Alegre, v. 40, n. 4, p. 1079-1102, out./dez. 2015.1083 
Medicalização dos Modos de Ser e de Aprender

tipo europeu a partir do Século XVIII” (Foucault, 2010a, p. 192). Foucault acolhe a expressão medicalização da vida, mas procura colocar em evidência o processo de funcionamento das instituições do saber e do poder médicos como um conjunto de procedimentos que inventam uma sociedade da norma. Foucault amplia o uso do conceito medicalização, pois fala da apropriação, pela sociedade, dos saberes médicos reconhecidos como discurso com efeitos de verdade nas mais diferentes esferas sociais, disciplinando e governando a vida de todos e de cada um. A essa tecnologia de poder Foucault chamou de biopoder:

Ao que essa nova técnica de poder não disciplinar se apli-
ca é - diferentemente da disciplina, que se dirige ao cor-
po - a vida dos homens, ou ainda, se vocês preferirem, ela
se dirige não ao homem-corpo, mas ao homem vivo, ao
homem ser vivo; no limite se vocês quiserem, ao homem-
-espécie. Mais precisamente, eu diria isto: a disciplina
tenta reger a multiplicidade dos homens na medida em
que essa multiplicidade pode e deve redundar em corpos
individuais que devem ser vigiados, treinados, utilizados,
eventualmente punidos. E, depois, a nova tecnologia que
se instala se dirige à multiplicidade dos homens, não na
medida em que eles se resumem em corpos, mas na medi-
da em que ela forma, ao contrário, uma massa global, afe-
tada por processos de conjunto que são próprios da vida,
que são processos como o nascimento, a morte, a produ-
ção, a doença, etc. (Foucault, 2010b, p. 204).

Foucault (2010b) alerta para a ressonância deste conceito que gera uma intensidade de discussões: “[...] a atenção da opinião pública mundial para o problema do funcionamento [...] das instituições do saber e do poder médicos" (Foucault, 2010b, p. 167). Refere ainda que a medicina social não existe, porque toda a medicina já é social. A medicina individualista, clínica, do colóquio singular, seria apenas um mito mediante o qual se defendeu e justificou certa forma de prática social da medicina: o exercício privado da profissão.

Foucault, em sua conferência intitulada ONascimento da Medicina Social, problematiza se a medicina moderna, nascida nos fins do século XVIII, com o aparecimento da anatomia patológica, é ou não individual. Em sua análise, procura mostrar que "[...] a medicina é uma prática social que somente em um de seus aspectos é individualista e valoriza as relações médico-doente" (Foucault, 2011, p. 79). Para ele, toda medicina é social, mas pode ser do tipo individual ou coletiva, e é definida em razão da intervenção médica e de seu objeto. Foucault (2011) apresenta reflexões sobre o livro de Victor Bullough (The Development of Medicine as a Profession, de 1965), analisando a apresentação deste autor sobre a história da medicina na Idade Média. Naquela época, a medicina era do tipo individualista e as dimensões coletivas eram discretas e limitadas. Segundo Foucault, com o desenvolvimento do capitalismo se deu um processo de socialização da medicina; o corpo tornou-se força de

1084 Educação \& Realidade, Porto Alegre, v. 40, n. 4, p. 1079-1102, out./dez. 2015. 
produção, de trabalho, e essa concepção foi criando a necessidade de governar a sociedade por meio do controle do indivíduo, investindo-se inicialmente no biológico e corporal, para posteriormente ser possível controlar as consciências e ideologias. Portanto, não há um processo de coação pela medicina, mas de produção, de um poder direcionador dos modos de olhar para o mundo, governar a si mesmo e aos outros; criar condições de vida. Foucault não concorda que existam dois movimentos diferenciados (medicina e antimedicina, assim como afirmava Illich), negando a existência de duas perspectivas antagônicas.

Afirma Foucault: "O que rege a sociedade não são os códigos, mas a perpétua distinção entre o normal e o anormal, o perpétuo empreendimento de restituir o sistema de normalidade" (2010a, p. 181). Com isso, discute o processo de medicalização como instituição de normas que regulam a vida cotidiana, como um processo de conduzir condutas, governar a vida. Para Foucault, “[...] o diabólico é que, cada vez que se quer recorrer a um domínio exterior à medicina, descobre-se que ele já foi medicalizado" (2010a, p. 184). Apesar de não fazer uso sistemático do termo medicalização, Foucault (2010a) faz referência ao processo quando analisa a constituição de uma sociedade na qual o indivíduo e a população são governados por saberes da medicina. Neste sentido, Foucault fala do desenvolvimento de um poder sobre a vida, a partir do qual os saberes médicos passam a permear todas as esferas sociais e constituem-se como relações de poder. Estas práticas conduzem, movimentam, se espalham, funcionam como uma maquinaria social que não está situada em um lugar e se dissemina por toda a estrutura social. Os saberes médicos foram historicamente produzindo discursos, resistências, formas de saber e de poder.

O dispositivo de medicalização se engendra das mais variadas maneiras no contexto no qual estamos inseridos. Roberto Machado, em seu livro Danação da Norma utiliza o termo "medicalização da sociedade” (1978), afirmando ser este processo intensificado na atualidade. Para este autor, a medicalização da sociedade

\begin{abstract}
[...] é o reconhecimento de que a partir do século XIX a medicina em tudo intervém e começa a não mais ter fronteiras; é a compreensão de que o perigo urbano não pode ser destruído unicamente pela promulgação de leis ou por uma ação lacunar, fragmentária, de repressão aos abusos, mas exige a criação de uma nova tecnologia de poder capaz de controlar os indivíduos e as populações tornando-os produtivos ao mesmo tempo que inofensivos; é a descoberta de que, com o objetivo de realizar uma sociedade sadia, a medicina social esteve, desde sua constituição, ligada ao projeto de transformação do desviante - sejam quais forem as especificidades que ele apresente - em um ser normalizado [...] (Machado, 1978, p. 156).
\end{abstract}

Esse movimento da medicalização na vida social torna visível a ação do dispositivo na vida de cada um e de todos. Um dispositivo cons-

Educação \& Realidade, Porto Alegre, v. 40, n. 4, p. 1079-1102, out./dez. 2015. 1085 
tituído de linhas que transitam, se conectam, se relacionam inventando modos de viver. Os indivíduos passam a se organizar e se comportar de acordo com as normas médico-sanitárias baseados na racionalidade médica que indicava como prevenir determinadas doenças. Esse processo de medicalização se atualiza, desenhando diferentes contornos também no âmbito escolar.

\section{Medicalização: práticas de normalização escolar}

O termo medicalização tem sido usado em diferentes perspectivas. Por um lado identifica-se a racionalidade médica como uma força produtora de discursos que funcionam e definem modos de ser e estar no mundo. Outros usam o termo como sinônimo do ato de medicar, quando seria necessário reconhecer que o ato de medicar é um dos tentáculos da medicalização - talvez o mais visível, ou mesmo o mais possível de contabilizar. E os números são pródigos quanto ao aumento de adoecimentos que necessitam de medicação. Cada vez mais assistimos a um processo amplo de medicação para tratar, minimizar, aniquilar sentimentos e ações que fazem parte da vida: tristeza, euforia, preguiça, baixa autoestima, desânimo, falta de criatividade, agitação.

Gaudenzi e Ortega mencionam que muitos autores utilizam o termo medicalização como "[...] crítica negativa ao excesso de medicação denunciando o aumento da intervenção médica em campos que até então não lhe pertenciam" (2012, p. 22). Esses autores apontam uma "intervenção política da medicina no corpo social, por meio do estabelecimento de normas morais de conduta e prescrição e proscrição de comportamentos, o que tornaria os indivíduos dependentes dos saberes produzidos pelos agentes educativo-terapêuticos" (Gaudenzi; Ortega, 2012, p. 22).

No âmbito do presente texto, o conceito de medicalização tem sido um disparador para analisarmos os processos que se referem à transformação de questões culturais, sociais, políticas em questões médicas. A medicalização funciona como um rastro de pólvora que se infiltra e se expande rapidamente de forma quase incontrolável em todas as esferas da vida humana. Segundo Barros (2010, p. 89):

$$
\begin{aligned}
& \text { De forma crescente e intensa, medicamentos são utiliza- } \\
& \text { dos para propósitos que extrapolam a função precípua } \\
& \text { para a qual, em tese, foram sendo descobertos e criados, } \\
& \text { isto é, aliviar sintomas e curar doenças. Interesses mer- } \\
& \text { cantis incentivam, fortemente, a crença na 'pílula mági- } \\
& \text { ca', pretensa solução para tudo. }
\end{aligned}
$$

Estamos falando não de um consumo de psicofármacos para buscar a cura de uma doença real, mas de um tipo de intervenção química no corpo para supostamente regular o que está aparentemente desregulado; um modo de gerir estilos de vida, governar comportamentos por

1086 Educação \& Realidade, Porto Alegre, v. 40, n. 4, p. 1079-1102, out./dez. 2015. 
meio de uma ação medicamentosa ${ }^{6}$. A história da medicina é, também, uma possibilidade de saber como essa área de conhecimento deixa de ser o estudo das doenças e passa a ser o campo de produção da normalidade, de definição do que a caracteriza, da potencialização/otimização ${ }^{7}$ do corpo e da vida. A medicina está envolvida com todo campo de relações do homem com a vida. A partir da inserção de seus conhecimentos nos diferentes espaços, as práticas sociais se apropriam da racionalidade médica, e produzem cada vez mais uma demanda dirigida aos serviços de saúde e à necessidade de intervenções medicamentosas no organismo. O campo da medicina produz discursos que definem como devemos ser, quais hábitos devemos ter para nos mantermos o maior tempo possível saudáveis, afinal entende-se que saúde é o que importa. Nesse sentido, Moysés afirma (2008, p. 1):

Com o consentimento da sociedade, que delega à medicina a tarefa de normatizar, legislar e vigiar a vida, estão colocadas as condições históricas para medicalização da sociedade, aí incluídos comportamento e aprendizagem.

Os discursos, compostos por uma rede de saberes produzidos pelos campos da medicina, psiquiatria, psicologia e pedagogia, produzem um solo fértil para a irrupção do processo de medicalização dos modos de ser e de aprender. É o modo como o sujeito se expressa na escola, se apresenta, fala, se veste, se comporta; é o seu processo de aprendizagem, como constrói relações, o ritmo na resolução das atividades utilizadas pela escola na elaboração dos discursos que apologizam o aluno. Os problemas de caráter pedagógico, político, social e cultural são traduzidos em questões biológicas e médicas. Esse fenômeno, chamado neste artigo de medicalização dos processos de aprendizagem, refere-se à prática de se tomar um problema que não é médico e dar-lhe uma roupagem, transformá-lo em um problema biológico centrado no indivíduo. É compreender a vida escolar a partir de uma lógica médica, relacionando aquilo que não está adequado às normas escolares (que não se enquadra nas performances escolares consideradas como metas em períodos estipulados) a uma suposta causalidade orgânica. São produzidos problemas com uma característica de causa biológica. Sendo esta a principal questão considerada como um indicador das supostas dificuldades escolares, as intervenções direcionam-se à busca de acompanhamento e controle da doença. Ao se considerar a composição orgânica como uma engrenagem falha, produz-se um discurso em que as grandes questões políticas e sociais são transformadas artificialmente em um problema do indivíduo.

Segundo Machado (2004, p. 2) ${ }^{8}$,

Passou a ser senso-comum pensarmos que as conquistas dependem dos esforços individuais de cada um. É comum assistirmos a programas na televisão que relatam histórias nas quais se reforça a ideia de que as pessoas, indivi-

Educação \& Realidade, Porto Alegre, v. 40, n. 4, p. 1079-1102, out./dez. 2015.1087 
dualmente, é que precisam lutar para conseguirem o que querem. O sistema capitalista se constitui nesta ideologia - defende que as pessoas que fracassam não aproveitaram bem as oportunidades que lhes foram dadas. Ora, pensar assim é fortalecer a ilusão de que vivemos condições de possibilidade igualitárias. O preço dessa ilusão é a privatização da responsabilidade pública e suas consequentes doenças contemporâneas no corpo do sujeito.

Esse discurso produz crianças incapazes de aprender e, também, a necessidade de um tipo de intervenção que deixa o pedagógico de lado e dá lugar a uma intervenção relacionada aos saberes médicos. Esse modo de gerir os processos de escolarização tem se infiltrado no pensamento cotidiano, como se fosse a única alternativa para a educação: patologizar aqueles que a escola não consegue alcançar. As doenças da não-aprendizagem criam uma demanda dirigida aos serviços de saúde, às intervenções específicas; nem sempre tais intervenções são propostas com o intuito de potencializar a capacidade dos alunos, mas, em muitos casos, apenas visam transformar o aluno produzido pelo discurso da anormalidade em um sujeito mais próximo possível da norma. O processo de medicalização acalma conflitos. Se o suposto problema está no aluno, ninguém tem culpa da sua doença. O discurso direcionado ao aluno comumente sintetiza: não é caso para o pedagógico, mas para a saúde.

\section{A Medicalização no Processo Escolar}

Pensar a relação do processo de medicalização na escolarização é abrir brechas para questionar que tipo de escola estamos construindo e para quais alunos. A escola tem se mostrado como lócus privilegiado desse processo de medicalização da vida. Essa concepção não é recente. Com o ingresso dos médicos higienistas nas escolas - processo que, no Brasil, se intensifica nos anos de 1920 - esse contexto passa a ser analisado como uma instituição com potencialidade para construir uma sociedade moral e fisicamente mais sadia. Machado (1978) aborda o olhar médico atento ao local e ao funcionamento da escola; a medicina social criticava as escolas existentes no Rio de Janeiro:

\footnotetext{
[...] nelas, as crianças não encontravam as condições que permitiriam seu sadio desenvolvimento. Reunidas geralmente em grande número, são jogadas por um diretor ignorante de higiene em uma mesma casa pouco asseada, situadas em ruas acanhadas e tortuosas, no centro da cidade, muitas vezes próxima a hospitais - cujas emanações mórbidas infectam o ar - ou a quartéis - onde se passam cenas testemunhadas pelas crianças. Além disso, a educação que recebem na escola volta-se basicamente para os livros, desprezando-se a educação do corpo (Machado, 1978, p. 297).
}

1088 Educação \& Realidade, Porto Alegre, v. 40, n. 4, p. 1079-1102, out./dez. 2015. 
A criança passa a ser vista como peça fundamental para o desenvolvimento e progresso de uma nação. Para Machado (1978) emerge, dessa nova exigência, o controle da vida da criança por meio dessa instituição voltada para ela. Tal exigência seria justificada pela importância da criança para a sociedade, pois o progresso só poderia ocorrer com o desenvolvimento saudável de cada indivíduo. Nesse sentido,

\begin{abstract}
[...] não aplicar o saber médico no estabelecimento de ensino significa comprometer o futuro da sociedade e, mais imediatamente, tornar o colégio, de centro de formação de cidadãos sadios e úteis que deve ser, em uma ameaça a seus internos (Machado, 1978, p. 298).
\end{abstract}

Ou seja, a escola era tida como o local mais apropriado para defender a saúde física e moral desde a mais tenra idade. A presença médica ali foi se apropriando não apenas de um espaço - a enfermaria, por exemplo - mas ocupando toda a escola com seu poder de decisão e organização desde os estudantes, professores, organização das salas de aula e intervenção nos conteúdos que deveriam compor o currículo. "Nada deve escapar ao poderoso olhar que tudo conhece, que por todo lugar penetra. Olhar tanto mais poderoso por ser sábio” (Machado, 1978, p. 302). Em relação à intensa e múltipla atuação dos médicos na escola, Stephanou (1999) afirma que pelo menos até os anos de 1930 não se encontravam demandas explícitas conclamando os médicos a assumirem um papel de responsabilidade nas questões educativas. No entanto, com a medicina tomando para si a tarefa de conduzir a humanidade a um estado hígido e civilizado, a educação do povo era uma prática imprescindível para se alcançar tal objetivo. A atuação do médico na escola voltou-se, segundo a autora, tanto para a coletividade escolar como para cada indivíduo em particular, fossem eles alunos, funcionários ou professores. Nesse sentido Stephanou (1999, p. 63) afirma:

A educação aparecerá como aquela tarefa mais afinada com a missão da medicina preventiva. Mas à medicina social, profilática por excelência, incumbiam também as ações corretivas e ortopédicas. Nesse sentido, para os médicos, a educação não se resumia a uma instrução elementar. Defendiam uma educação física, intelectual, sexual, mental, enfim, moral, dos indivíduos, para o que empreenderam iniciativas concretas, seja da educação escolar, seja da educação popular e propaganda sanitária. Embora reconhecendo que o espaço concreto da cidade apresentava-se como espaço pedagógico por excelência, indicavam que a higienização dos espaços era indissociável de uma higienização individual.

O processo de medicalização na escola desenvolveu-se com a urbanização e a consequente inserção dos higienistas nas instituições escolares com o intuito de propagar a educação sanitária por meio de uma atuação formativa e contínua. Os médicos instituíram-se como educa-

Educação \& Realidade, Porto Alegre, v. 40, n. 4, p. 1079-1102, out./dez. 2015.1089 
dores sociais, já que reconheciam a necessidade de uma ação educativa dirigida a toda população. Esses médicos consideravam a saúde e a educação como as primeiras necessidades do povo. Nesse sentido, a escola torna-se o espaço pedagógico por excelência, tendo como meta inculcar, desde cedo, as ideias que constituíam o ideal higienista de produzir cidadãos civilizados, conscientes da importância do cuidado de si, contribuindo para o progresso da nação. Almejar o progresso significava incorporar métodos considerados científicos tanto no campo da educação como naquele da saúde, e isso deveria ser feito por meio de práticas pedagógicas. A escola, portanto, torna-se o lugar onde os discursos pautados na racionalidade médico-higienista ecoam, se multiplicam, se atualizam e possibilitam uma ação extensiva sobre a população, incidindo sobre seus costumes. Stephanou (1999), ao analisar os discursos médicos nas primeiras décadas do século XX e suas implicações no âmbito escolar, apresenta como foi se produzindo a emergência de uma parceria entre educação e saúde.

O Dr. Vianna ilustra com vigor a vertente da Medicina que creditava à Educação o sucesso das providências higiênicas: preparar o povo, subtraí-lo da ignorância, sensibilizar as consciências, produzir novos costumes para abolir as intimidações e as medidas coercitivas, de resultados duvidosos e efêmeros. Através da educação os indivíduos tornar-se-iam agentes de sua própria saúde, irradiando-a no lar, no trabalho, na coletividade (Stephanou, 1999, p. 306).

A autora mostra como as ações médicas foram se tornando múltiplas, intensas e potentes no sentido de formular propostas de saneamento, analisar o tipo brasileiro, propor estratégias de educação e propagandas sanitárias através de cursos, conferências, conselhos médicos, divulgação por meio da imprensa, análise dos currículos escolares e propostas de inserção de conteúdos médicos e, ainda, a produção de uma circulação intensa de manuais de saúde e higiene. A formação do cidadão nas primeiras décadas do século XX evidencia a preocupação dos cuidados pessoais nos domínios da urbanidade, da higiene e da saúde por meio de práticas que deveriam conduzir ao governo de si mesmos em relação às condutas, ajustando-as aos novos modos de sociabilidade urbana. Eis um processo de medicalização tornando-se potente por meio do ambiente escolar.

A medicalização, como ocorre com os fenômenos humanos em geral, não tem limite, pontos de partida ou de chegada, atravessa todos os campos da vida, compõe a vida, e é na escola que esse dispositivo se potencializa, ganhando intensa visibilidade por meio da classificação de condutas.

A Educação, assim como todas as áreas sociais, vem sendo medicalizada em grande velocidade, destacando-se o fra-

1090 Educação \& Realidade, Porto Alegre, v. 40, n. 4, p. 1079-1102, out./dez. 2015. 
casso escolar e seu reverso, a aprendizagem, como objetos essenciais desse processo (Collares; Moysés, 1994 p. 26) ${ }^{9}$.

A medicalização no contexto da escola é uma prática que explica os fenômenos chamados de fracasso escolar, a partir da racionalidade médica. Trata-se de transformar crianças em crianças anormais. Prolifera-se, desse modo, um discurso com status de verdade ao se considerar que esses alunos - que supostamente não aprendem - têm um problema com explicação de ordem médica. "O que está em jogo é um violento processo de medicalização de crianças cujo desempenho na escola não corresponde exatamente ao padrão esperado" (Garrido; Moysés, 2011, p. 150).

Trata-se de uma prática de condução, de gestão de um modo de vida, da maneira através da qual cada aluno se expressa e constrói a relação com o aprendizado. Um exemplo importante que nos induz a problematizar a questão da patologização dos modos de ser e de aprender é a grande dificuldade proclamada na área da leitura e da escrita que tem instaurado um processo explicativo que não mais questiona a escola, o método ou as condições de aprendizagem e de escolarização. Buscam-se na criança, em áreas de seu cérebro, em suas condutas e modos de expressão as causas das dificuldades de leitura, da escrita e consequentemente a justificativa para a suposta incapacidade de acompanhamento dos conteúdos escolares. A criança com dificuldades na leitura e escrita é rotulada, procuram-se as causas, apresenta-se o diagnóstico e em seguida prescrevem-se basicamente dois tipos de intervenção: a medicação ou o acompanhamento terapêutico. Essa dificuldade, que diz respeito ao processo de escolarização de muitos alunos, tem sido comumente nomeada como dislexia e passa a ser constituída como distúrbio. Considerada essa limitação como distúrbio, pouco ou nada a escola acredita poder intervir por meio das práticas pedagógicas.

Outra situação tomada como ponto de problematização da medicalização dos modos de ser e de aprender é a justificativa da não aprendizagem em função de uma desnutrição. Collares e Moysés (1994) ${ }^{10}$ citam criticamente o fato de a relação entre desnutrição e fracasso escolar ter sido objeto de muitos trabalhos científicos. Apesar da intensidade das críticas a essa associação simplificadora, há continuidade de discursos que consideram a desnutrição como causa da não-aprendizagem. São duas vertentes que as referidas autoras sinalizam como sendo base do processo daquilo que chamam de patologização do fracasso escolar: uma delas é tomar o fracasso escolar como consequência da desnutrição; a outra, como o suposto fracasso escolar ser explicado como resultado da existência de disfunções neurológicas. As autoras afirmam ainda que, apesar da intensidade da crítica em relação a esse tipo de associação (entre desnutrição e não aprendizagem), ela ainda está presente nos discursos escolares - sobretudo no que tange à população menos favorecida, para justificar a suposta não-aprendizagem de terminados alunos. Afirmam, 
Os mitos, as crenças resistem inabalavelmente ao confronto com a realidade. No máximo, transmutam-se em aparentes novos mitos, novas crenças, para permanecerem exatamente iguais (Collares; Moysés, 1994, p. 28).

Transforma-se, desse modo, algo que diz respeito à relação pedagógica em supostos distúrbios, como temos visto atualmente com diagnósticos de dislexia, déficit de atenção e hiperatividade, entre outros. Crianças que em uma dada época eram tidas como levadas, sapecas, introvertidas, agitadas, teimosas, indisciplinadas agora são diagnosticadas com os mais diversos transtornos, déficits, desvios ${ }^{11}$.

Atualmente, essa distorção, esse grande hall de rotulações, direciona-se a todas as crianças, independente de sua classe econômica. Filhos de pais alcoólatras, drogados, crianças oriundas de famílias desestruturadas, com pais ausentes: essas crianças têm seu histórico de vida analisado como causadores de seu suposto fracasso escolar. Uma condição de vida considerada desregrada torna-se justificativa de provável fracasso e, desse modo, a escola exime-se de uma análise mais abrangente e contextualizada daquilo que foi categorizado como problema de aprendizagem.

O problema do fracasso escolar ${ }^{12}$ (Abreu, 2006; Collares; Moysés, 1992; Patto, 1999) é individualizado, negando-se as relações escolares estabelecidas ao longo do processo de escolarização. A criança ou o jovem que não respondem adequadamente aos aprendizados que a escola exige, e não se enquadra em relação aos comportamentos determinados como adequados, dá evidências à medicalização na instituição. Questões interpretadas como problemas capazes de produzir o fracasso escolar são tratadas como déficits ou problemas biológicos, ignorando-se as diferentes influências dos modos de ser e de aprender.

Segundo Baptista (2006, p. 40), a

[...] educabilidade de todos os sujeitos, o potencial de modificabilidade que existe em todas as pessoas, a compreensão de que nos constituímos em situações que devem ser contextualizadas historicamente, e, portanto, o verbo 'estar' parece sempre mais potente para descrever nosso interlocutor (e a nós mesmos) do que o 'ser'. Somos transitoriedade, modificamo-nos continuamente.

A medicalização dos modos de ser e de aprender se constitui como negação do verbo estar, afetando a todos os escolares em um processo que se infiltra sorrateiramente por todas as frestas da escola. Há inúmeras formas de resistência à medicalização, umas mais perceptíveis do que outras: corpos em movimento constante, outros no silêncio paralisante. Alunos que dormem em aula, não participam das atividades, incorporam ou corporalizam ${ }^{13}$ os discursos que produzem seus modos de ser como patológicos. Neste artigo, são apresentados fragmentos ilustrativos da relação de uma professora com seu aluno Valentin ${ }^{14}$. Os diálogos tomados como exemplos compõem cenas que tornam visível a

1092 Educação \& Realidade, Porto Alegre, v. 40, n. 4, p. 1079-1102, out./dez. 2015 
presença dos discursos medicalizantes no contexto escolar. Neste caso, o aluno Valentin parece ter assumido os valores, categorias e modelos médico-explicativos. No entanto, Valentin foi um aluno que lutou para não incorporar um diagnóstico. Quase mudou sua maneira de ver a vida e a si próprio. Os rumos de sua trajetória, em função do olhar normativo, poderiam ter definido outro percurso escolar. Caponi (2010, p. 140) enfatiza:

\begin{abstract}
As classificações humanas geram efeitos nos sujeitos: cada classificação, cada diagnóstico, cada tipificação de pessoas, implica uma mudança no modo como agimos, como expressamos nossas emoções e sentimentos, no modo, enfim, de nos construirmos como sujeitos.
\end{abstract}

Valentin era expansivo, suas intensidades, seus movimentos quase incontroláveis foram considerados patológicos pela escola e seu modo de ser foi classificado pelo saber médico, nomeado, rotulado como R46.3 $3^{15}$. O que dizem essa letra e esses números sobre Valentin? Um diagnóstico construído em um curto espaço de tempo entre médico e criança. Valentin comentou: "o médico mal me olhou... Nem me botou a mão”. Valentin precisava ser controlado, disciplinado, docilizado. Ele "[...] entra numa maquinaria de poder que o esquadrinha, o desarticula e o recompõe” (Foucault, 2009, p. 133).

A seguir, Valentin constrói com sua professora um diálogo, tornando visível o dispositivo da medicalização em seu pleno funcionamento.

\title{
Medicalização dos Modos de Ser e Aprender em Funcionamento
}

Em 2010, quando ocorreram as cenas aqui apresentas, o menino Valentin estava com nove anos. Gostava de expressar suas ideias, fazer comentários em sala de aula em relação ao que estudava. Vestia-se de maneira peculiar. Na época estava sendo exibida a telenovela brasileira intitulada "Ti ti ti". Havia um personagem infiltrado no mundo da moda e, para isso, inventou o nome de Victor Valentin, disfarçando-se de estilista espanhol. Victor Valentin usava uma boina de lado, roupas tipicamente espanholas. Valentin, aluno, também usava boina e camisas para dentro da calça jeans. Por vezes ia para a escola de sapato, e não tênis, como é mais frequente para crianças de sua idade. Destacava-se dos demais colegas por ter um estilo original. Por isso o nome fictício da criança foi escolhido para esse texto. Sempre pareceu ser um menino destemido. Chegou à escola sendo considerado um menino com dificuldade na aprendizagem.

Os trabalhos de escrita feitos em outra escola foram solicitados pela professora para que fosse possível acompanhar a produção escrita do aluno. No entanto, não foi possível tomá-los como instrumento de

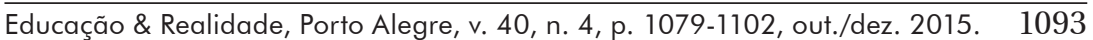


apoio didático para analisar a produção textual. Estavam todos marcados com expressões como: letra horrivel, texto incompreensível, melhorar a letra. Não havia comentários sobre o conteúdo da escrita e sobre as ideias desenvolvidas por Valentin.

Professora: Valentin, se tiveres, gostaria que me trouxesses os textos feitos por ti na outra escola. Gostaria de dar uma lida.

Valentin: Mas, professora, não vais entender nada, minha letra é horrível. Não sei escrever.

Professora: Primeiro traga e depois olhamos juntos.

Valentin: Estou avisando que não vais conseguir entender nada.

Valentin já anunciava uma visão sobre si mesmo: "não sabia escrever". No entanto, quando levou os textos, leu para a professora. Os textos tinham uma história coesa e, na maioria das vezes, com certo tom de humor. Os rabiscos feitos pela professora nos textos não se referiam ao conteúdo, mas valorizavam apenas a forma da letra. A partir desse discurso, o menino foi se vendo como alguém sem capacidade para escrever. Essa questão ultrapassa o desenho da letra, pois trata-se da produção de um sujeito que se insere em um lugar de falha, fracasso. A professora se perguntava: "Como retomar o sentido da escrita? Como mostrar o valor do que está escrito?”, Valentin sabia escrever e escrevia bem.

Valentin se autoafirmava, produzia seu lugar como original, não participava de uma hierarquia da norma onde deveria seguir um modelo, não era cópia dos padrões de aluno ideal produzidos historicamente. Produzia novos modos de olhar, de pensar, invocava a invenção de práticas pedagógicas, pois ele tornava visível a possibilidade de ser, constantemente, múltiplos outros.

O menino ganhou esse apelido dos colegas, e, como muito se discutia na turma a questão de apelido - só poderia ser colocado em um colega quando fosse carinhoso e permitido -, Valentin, ao ouvir ser chamado dessa maneira reclamou:

Valentin: Professora, não gosto desse apelido.

Professora: Ué, por quê? Não é um apelido ofensivo. Sabes por que te chamam assim?

Valentin: Sei, é porque na novela tem o Victor Valentin, que se veste como eu. Mas não sou Victor Valentin, sou [...].

Nesse momento ele fala seu nome, reafirma não ser outro, não pode ser comparado, tem personalidade, não é cópia, é único. Assim o aluno foi construindo sua trajetória escolar, se afirmando, expondo suas opiniões, seus desejos, suas angústias e denunciando tudo que a ele desagradava. Esses breves excertos mostram como Valentin se insere no mundo; é um menino que apresenta positividade, se afirma, é intenso. Apresenta-se ao mundo na primeira pessoa e isso incomoda a escola, pois essa instituição, em geral, não sabe lidar com o posicionamento e com as resistências dos alunos.

1094 Educação \& Realidade, Porto Alegre, v. 40, n. 4, p. 1079-1102, out./dez. 2015. 
Valentin foi enviado ao serviço de saúde para ser diagnosticado. Uma professora substituta eventual da professora titular sugeriu o encaminhamento do aluno. Essa professora substituta fazia queixas à orientação escolar sobre o modo agressivo do aluno, por falar o que pensava, por não saber se controlar e causar tumulto em aula. Em um determinado dia, Valentin gritou com a professora, estava agitado e bravo. Alguns colegas estavam brigando, e a professora continuou a aula sem fazer nenhum tipo de intervenção em relação à briga. Valentin não se conteve e perguntou se ela não enxergava o que estava acontecendo (sobre isso, disse que a professora fingia não ver o que acontecia em sala), e resolveu sair porta afora para chamar a direção e resolver o problema. Essa atitude de Valentin poderia ter sido vista de diferentes maneiras, mas a professora considerou-a como desrespeito, abuso, falta de controle e, assim, conversou com o responsável pelo aluno e comentou sobre sua suposta hiperatividade.

Valentin mostra, nas diferentes cenas protagonizadas, o dispositivo da medicalização a pleno vapor. Os discursos sobre ele indicam que há algo de errado em seu modo de ser, de se vestir, de falar, de se expressar; um modo de ser causador de tumultos e que desorganiza a escola. Punindo Valentin com um diagnóstico, mostra-se aos demais colegas que esse modo de ser criança, aluno, não é adequado ou normal. Essas séries de elementos que falam de Valentin mostram como a criança é envolvida pela medicalização, mas também anunciam os pontos de resistência que ficam evidentes quando o menino afirma seu nome, diz ser o personagem da novela a imitá-lo; manifesta-se quando sai de sala de aula, por achar que a professora não agiu como deveria. Essas ações de Valentin tornam visível um modo de resistir ao processo de medicalização.

Valentin: Professora, fiquei sabendo ontem que preciso de um remedinho. Sabia que sou hiperativo?

Professora: Como assim, Valentin? Quem te disse isso?

Valentin: Fui na médica e ela disse que sou hiperativo, que não paro e que preciso tomar um remédio para aprender. A médica disse que sou hiperativo e que isso é um tipo de doença que tem cura. Que é só tomar remédio. Professora: Tu sabes o que significa isso, Valentin?

Valentin: Sei, professora. É que eu não paro quieto, sou atrapalhado, às vezes falo alto e também sou meio agressivo. Preciso ficar mais calmo. Eu sou assim mesmo, tu não achas, professora? Eu tenho essa doença? Preciso de remédio?

Professora: Valentin, claro que não estás doente. O que eu acho é que é muita saúde para um corpinho tão pequeno. Tens muitas informações, és muito inteligente e te empolgas em mostrar tudo que sabes.

Valentin olhou sorrindo para sua professora e continuou a ser empolgado, inteligente, culto, interessado em aprender e ensinar e, sobretudo, a desafiar - atributos esses considerados pela escola como sintomas de um possível transtorno. As formas de comportamento de Valentin tornaram-se sintomas de uma suposta patologia.

Educação \& Realidade, Porto Alegre, v. 40, n. 4, p. 1079-1102, out./dez. 2015.1095 
Esse menino era considerado por alguns uma criança agitada. Ria muito, falava depressa, empolgava-se ao dividir saberes, mostrava um modo de ver o mundo extremamente criativo. Tinha pressa em mostrar a todos tudo que sabia e achava interessante. Por vezes, o conteúdo e as atividades trabalhados em aula lhe pareciam tão motivadores que pedia para ficar de pé para falar, escrever, fazer os exercícios, comentar, responder. Fazia piadas inteligentes, era perspicaz. Uma história de vida escolar tornada problema, mas transformada por Valentin em aprendizado, em possibilidade de se (re)construir constantemente.

Valentin resistiu ao processo de medicalização de seus modos de ser e aprender, mas, também, participou do processo de incorporação do saber médico, e isso se torna visível quando se refere a si mesmo como hiperativo, mostrando ter consciência do significado do termo. Com esse diálogo é possível vermos a medicalização em ato; um dispositivo que nos produz e se renova constantemente; convoca-nos a problematizar a diferença entre uma doença a ser tratada e uma singularidade a ser reconhecida. Expropriadas de sua normalidade, muitas vezes as crianças incorporam a ideia da doença, de que são fracas, têm falhas e são incapazes. Na luta pela sobrevivência na escola, incorporam o rótulo e carregam o peso do estigma. A escola ainda se configura baseada em uma metodologia que, em grande parte, continua pautada em um único modo de ensinar a mesma coisa a todos. Quem não consegue acompanhar esse processo educativo fica à margem dos conhecimentos produzidos na instituição. Qual escola para a criança contemporânea? A medicalização dos modos de ser e aprender evidencia a atualidade do funcionamento institucional da escola, nos mostra os acontecimentos nesse tempo de uma ampliação do processo de escolarização. A medicalização da aprendizagem é um problema político e social. É um processo de enfraquecimento do sujeito. Esse mal tem remédio?

\section{Retornando aos Desafios: finalizando reflexões}

Este artigo teve por objetivo analisar o processo de medicalização dos modos de ser e aprender no espaço escolar. Esse dispositivo - a medicalização - tem se intensificado na escola, trazendo à tona explicações centradas nos discursos embasados na racionalidade médica para justificar processos de escolarização considerados de não-aprendizagem. Para isso, foi analisado o conceito de medicalização como dispositivo e como ele se faz visível nas práticas escolares através dos discursos, sobre os alunos, que têm evidenciado uma tendência em transformar questões culturais, político-sociais e pedagógicas em patologias. Algumas perguntas tornaram-se potentes para que pudéssemos tornar visíveis as práticas escolares, produzindo conexões com discursos médicos patologizantes: Quais práticas pedagógicas a medicalização tem produzido? Que lugares de sujeito têm construído? Como esse dispositivo tem influenciado na concepção de ensinar e aprender? A partir desses

1096 Educação \& Realidade, Porto Alegre, v. 40, n. 4, p. 1079-1102, out./dez. 2015. 
questionamentos, percebemos o modo como a medicalização afeta a todos, mas a uns e outros de diferentes maneiras. As cenas vividas por Valentin permitiram analisar discursos que possibilitaram perceber o processo de produção de uma subjetividade patológica na escola. As rupturas produzidas a partir do discurso da professora se constituem como possibilidade de brechas para que um discurso potencialmente pedagógico seja construído. A palavra do professor é uma peça importante no jogo de saberes e poderes que produzem modos de ser aluno. Para a maioria dos alunos, sobretudo os que estão nos primeiros anos escolares, o que o professor diz é lei. Dizer a uma criança que está iniciando seu percurso escolar que ela tem problemas, distúrbios, que não irá conseguir avançar e que precisa de remédio ou de acompanhamento médico para aprender, tende a expropriá-la de suas potencialidades, como se, naquele corpo ${ }^{16}$, nada tivesse para ser construído, modificado, compartilhado.

A análise dos discursos produzidos sobre Valentin foi o movimento disparador para visibilizar os enunciados que dão sentido a uma determinada forma de existir no contexto escolar e se perpetuam, se enraízam, tornando-se verdades incontestáveis no interior desta cultura. Com o exemplo apresentado pela história desse menino, podemos perceber a medicalização em ação, em movimento, compondo uma vida escolar. Olhares, gestos, intensidades, palavras, estilos de vida tornam-se elementos de um olhar clínico, de um olhar que foi sendo construído no ambiente escolar, composto por discursos médicos que buscam, no sujeito, uma falha, uma deficiência, algo que possa justificar cientificamente o porquê de determinados alunos não aprenderem como os outros, justificar o fracasso escolar de vidas que não conseguem se enquadrar nas expectativas da escola.

As estratégias de construção de lugares são inúmeras, e podem se dar por meio de ações intituladas pedagógicas, definindo espaços que visam disciplinar o corpo. Junto a essas ações, em outros tantos momentos, a medicação fica em evidência, aliando-se a essas estratégias. Essa ação, de cunho pedagógico, pode ser percebida em discursos de pais, professores, alunos que consideram a necessidade de certas medicações - que tem por objetivo fazer os ajustes necessários - para que $\mathrm{o}$ aluno aprenda. Um exemplo que dá visibilidade à potência desse discurso é a fala da mãe de um menino enviado para avaliação psiquiátrica: "Vou dar Ritalina para escola", disse a mãe. Ao ser indagada sobre o que queria dizer com a afirmação "Ritalina para a escola", a mãe explica que o médico lhe havia dito que o remédio deveria ser dado um pouco antes de que o aluno fosse levado à escola, para que ficasse mais calmo e não incomodasse tanto; segundo a mãe, em casa ele não precisava de medicação, já que sabiam contornar os problemas. Nada de novo, quando pensamos a história do disciplinamento. A novidade está nas formas como isso tem se produzido (no processo de biologização, por exemplo), identificadas muitas vezes como científicas e, portanto, seguras.

Educação \& Realidade, Porto Alegre, v. 40, n. 4, p. 1079-1102, out./dez. 2015.1097 
Por que motivo indicar a medicação para que alguém possa frequentar um determinado espaço? Por que em casa os conflitos são vividos e amenizados, e na escola busca-se o silenciamento, a não-experiência, não-convivência? Patologizar, denominar como distúrbio um modo de expressão, um modo de aprender, é uma das tantas estratégias de subjetivação que a medicalização implica. Meira (2012, p. 140) afirma:

A medicalização constitui-se em um desdobramento inevitável do processo de patologização dos problemas educacionais que tem servido como justificativa para a manutenção da exclusão de grandes contingentes de crianças pobres que, embora permaneçam nas escolas por longos períodos de tempo, nunca chegam a se apropriar de fato dos conteúdos escolares.

Sabe-se que muitos alunos, embora tenham seu direito de acesso à escola garantido, não têm seus modos de ser e aprender respeitados e valorizados da mesma forma. São criadas diferentes maneiras de se dizer aos alunos que não fazem parte do grupo que se instituiu como aluno normal, aluno padrão, que há algo de errado com eles. A esses é negada, de certa forma, uma experiência ampla de escolarização, de convivência e de apropriação do que é estabelecido como conteúdo escolar, excluindo-os do processo de transformação humana pelas experiências com o outro.

Discutir sobre o processo de medicalização dos modos de ser e aprender é colocar em suspenso as verdades produzidas pela escola sobre o processo amplo de ensinar e aprender. É questionar as práticas pedagógicas, as configurações da escola, os espaços oferecidos. É duvidar dos discursos que percorrem os corredores escolares, se alastram e invadem todos os espaços, produzindo modos de ser aluno, construindo rótulos que definem o lugar que cada um e de todos. Afinal, para os problemas escolares haveria remédio ${ }^{17}$.

Recebido em 25 de agosto de 2013 Aprovado em 03 de fevereiro de 2014

\section{Notas}

10 título da música é Até o fim, de Chico Buarque.

2 Médico higienista que, nomeado por Anísio Teixeira, assumiu, em 1933, o serviço de ortofrenia e higiene mental do Distrito Federal.

3 Há estudos, como Abreu (2006) e Gaudenzi e Ortega (2012), que evocam possíveis usos do termo medicalização, em momentos precedentes a década de 1970, associando a extensão do âmbito da ação médica às diferentes esferas da vida.

4 Nosografia é a prática de classificação metódica das doenças (Dicionário Mor da Língua Portuguesa. Editora Pedagógica Brasileira, v. 3, 1967, org. José Francisco Moreira).

1098 Educação \& Realidade, Porto Alegre, v. 40, n. 4, p. 1079-1102, out./dez. 2015. 
5 José Augusto Cabral de Barros (2010, p. 91) afirma que essa terminologia é proveniente do texto de Ivan Illich (1975) para definir o processo de "invasão crescente da medicina" (Barros, 2010) em áreas da vida individual que passam a ser objetos da atenção médica, mesmo que não tenham "[...] sinais ou sintomas de caráter mórbido ou patológico" (Barros, 2010).

6 Os artigos que têm tratado o processo de medicação, como os de Valderrama (2010), Barros (2010), Hernáez (2010) e Hellmann e Vaz (2010), utilizam o termo medicalização referindo-se à banalização do uso de medicamentos, muitas vezes sem estar associado à doença. "Diferentes situações que assumem crescente atenção pelo fato de virem sendo instrumentalizadas com o propósito de 'vender doenças', terminam em transformar a todos em 'pacientes', isto é, potenciais consumidores de fármacos” (Barros, 2010, p. 91).

7 Segundo Nikolas Rose (2007, p. 38) o conceito de otimização propõe uma normalidade potencializada imaginando com isso um "aumento de sucesso". Segundo este autor a otimização se utiliza de ferramentas "tecnologias para melhoria cognitiva e emocional". Este processo “[...] não se limita a prometer a capacidade de lidar com a essa situação, ou mesmo a sua cura, mas a correção e melhoria do tipo de pessoa que somos ou quem queremos ser". No original: "[...] (le tecnologie di miglioramento cognitivo ed emotivo) non promettono semplicemente la capacità di far fronte alla situazione, o anche la guarigione, ma la correzione e il potenziamento del tipo di persone che siamo o che vorremo essere".

8 Encaminhar para a saúde quem vai mal na educação: um ciclo vicioso? - Texto publicado pela Revista Educação SME, 2004.

9 A Transformação do Espaço Pedagógico em Espaço Clínico. A Patologização da Educação. Ideias (UNICAMP), v. 23, p. 25-31, 1994.

\section{A transformação do Espaço Pedagógico em Espaço Clínico.}

11 Apesar da importância da temática relativa os processos diagnósticos, consideramos que o investimento na ampliação desse debate transcende os objetivos do presente texto. Procuramos manter nossa atenção dirigida aos processos de nomeação mais difusos, cotidianos, característicos das relações constitutivas dos sujeitos, mesmo que sejam nomeações desprovidas de uma legitimidade típica dos sistemas classificatórios.

12 Artigo (O médico higienista na escola: as origens da medicalização do fracasso escolar) baseado em parte da dissertação de mestrado da Profa. Ma. Patrícia Carla Silva do Vale Zucoloto, realizada sob orientação da Profa. Dra. Maria Helena Souza Patto, apresentada ao Programa de Pós-graduação em Psicologia Escolar e do Desenvolvimento Humano do Instituto de Psicologia da Universidade de São Paulo.

$13 \mathrm{O}$ termo corporalizar aqui significa não apenas incorporar, reunir intimamente, juntar-se ao corpo, mas transformar o próprio corpo como se este fosse patológico. Mostrar, por meio dos movimentos corporais, a patologia.

14 Nome fictício. As cenas apresentadas são fragmentos de diálogos que compõem o que denominamos de medicalização dos modos de ser e aprender. As cenas protagonizadas por Valentin são produzidas no contexto da prática pedagógica de uma das autoras do texto.

15 CID 10. R46 - Sintomas e sinais relativos à aparência e ao comportamento. R46.3 - Hiperatividade. Informações baseadas no Classificação Internacional

Educação \& Realidade, Porto Alegre, v. 40, n. 4, p. 1079-1102, out./dez. 2015.1099 
de Doenças e Problemas Relacionados à Saúde, também conhecida como Classificação Internacional de Doenças - CID 10. Disponível em: <http://www. medicinanet.com.br/cid10.htm>.

16 A palavra corpo é utilizada entendendo-o como um fenômeno histórico que constitui uma relação complexa entre o interior e o exterior, capaz de ser afetado de inúmeras maneiras.

17 A pesquisa a qual este artigo está vinculado foi financiada pela CAPES.

\section{Referências}

ABREU, Maria Helena do Rego Monteiro de. Medicalização da Vida Escolar. 2006. 100 f. Dissertação (Mestrado em Educação) - Universidade Federal do Estado do Rio de Janeiro, Rio de Janeiro, 2006.

BAPTISTA, Claudio Roberto. Inclusão em Diálogo: algumas questões que insistem. In: SEMINÁRIO NACIONAL DE FORMAÇÃO DE GESTORES E EDUCADORES, 3, 2006, Brasília. Ensaios Pedagógicos: educação inclusiva: direito à diversidade. Brasília: MEC, 2006.

BARROS, José Augusto Cabral de. Ampliando espaços para a "medicalização: instrumento para desfrute de melhores níveis de vida? In: CAPONI, Sandra et al. Medicalização da Vida: ética, saúde pública e indústria farmacêutica. Palhoça: Unisul, 2010. P. 89-95.

CAPONI, Sandra. Medicalização da Vida: ética, saúde pública e indústria farmacêutica. Palhoça: Ed. Unisul, 2010.

COLLARES, Cecília Azevedo Lima; MOYSÉS, Maria Aparecida Affonso. Diagnóstico da Medicalização do Processo Ensino-Aprendizagem no $1^{\circ}$ série do $1^{\circ}$ grau no Município de Campinas. Em Aberto, Brasília, ano 11, n. 53, jan./mar. 1992.

COLLARES, Cecília Azevedo Lima; MOYSÉS, Maria Aparecida Affonso. A Transformação do Espaço Pedagógico em Espaço Clínico (A Patologização da Educação). Revista Ideias, Campinas, v. 23, p. 25-31, 1994.

FOUCAULT, Michel. Vigiar e Punir: nascimento da prisão. Tradução de Raquel Ramalhete. 37. ed. Petrópolis: Vozes, 2009.

FOUCAULT, Michel. Crise da Medicina ou Crise da Antimedicina. Verve, São Paulo, n. 18, p. 167-194, ago./dez. 2010a. Disponível em: <http://revistas.pucsp. br/index.php/verve/article/view/8646/6432>. Acesso em: 28 abr. 2013.

FOUCAULT, Michel. Em Defesa da Sociedade: curso no Collège de France (19751976). Tradução de Maria Ermantina Galvão. São Paulo: Martins Fontes, 2010b.

FOUCAULT, Michel. Microfísica do Poder. São Paulo: Graal, 2011.

GARRIDO, Juliana; MOYSÉS, Maria Aparecida Affonso. Um Panorama Nacional de Estudos sobre a Medicalização da Aprendizagem de Crianças em Idade Escolar. In: Conselho Regional de Psicologia de São Paulo; Grupo Interinstitucional Queixa Escolar (Org.). Medicalização de Crianças e Adolescentes: conflitos silenciados pela redução de questões sociais a doenças de indivíduos. São Paulo: Casa do Psicólogo, 2011.

GAUDENZI, Paula; ORTEGA, Francisco. O Estatuto da Medicalização e as Interpretações de Ivan Illich e Michel Foucault como Ferramentas Conceituais para o Estudo da Desmedicalização. Interface, v. 16, n. 40, p. 21-34,

1100 Educação \& Realidade, Porto Alegre, v. 40, n. 4, p. 1079-1102, out./dez. 2015. 
jan./mar. 2012. Disponível em: <http://www.scielo.br/scielo.php?pid=S1414-32832012000100003\&script=sci_arttext>. Acesso em: 18 jun. 2013.

HELLMANN, Fernando; VAZ, Eliza. A Medicalização da Infância e o Uso de Florais de Bach no Cuidado à Saúde de Crianças com Transtorno de Déficit de Atenção e Hiperatividade. In: CAPONI, Sandra et al. Medicalização da Vida: ética, saúde pública e indústria famacêutica. Palhoça: Unisul, 2010. P. 229-242.

HERNÁEZ, Angel Martínez. A Medicalização dos Estados de Ânimo. O consumo de antidepressivos e as novas biopolíticas das aflições. In: CAPONI, Sandra et al. Medicalização da Vida: ética, saúde pública e indústria famacêutica. Palhoça: Unisul, 2010. P. 111-134.

ILLICH, Ivan. A Expropriação da Saúde: Nêmesis da Medicina. Rio de Janeiro: Nova Fronteira, 1975.

MACHADO, Roberto. Danação da Norma: Medicina social e a constituição da Psiquiatria no Brasil. Rio de Janeiro: edições Graal, 1978.

MACHADO, Adriana Marcondes. Encaminhar para a Saúde quem vai Mal na Educação: um ciclo vicioso? Revista Educação, São Paulo, SME, 2004. Disponível em: <http://efp-ava.cursos.educacao.sp.gov.br/Resource/153536,7A7/Assets/NucleoBasico/pdf/nb_m07t11b.pdf>. Acesso em: 06 ago. 2013.

MEIRA, Marisa Eugênia Melillo. Para uma Crítica da Medicalização na Educação. Revista Semestral da Associação Brasileira de Psicologia Escolar e Educacional, São Paulo, v. 16, n. 1, p. 135-142, jan./jun. 2012.

MOREL, Benedict-Augustin. Tratado das Degenerescências na Espécie Humana. Revista Latino Americana de Psicopatologia Fundamental, São Paulo, v. 11, n. 3, p. 497-501, set. 2008.

MOYSÉS, Maria Aparecida Affonso. A Medicalização na Educação Infantil e no Ensino Fundamental e as Políticas de Formação Docente. In: REUNIÃO ANUAL DA ASSOCIAÇÃO NACIONAL DE PÓS-GRADUAÇÃO E PESQUISA EM EDUCAÇÃO (ANPED), 31, 2008, Caxambu. Anais... Rio de Janeiro: Editores Associados, 2008.

ORGANIZAÇÃO MUNDIAL DA SAÚDE. Classificação de Transtornos Mentais e de Comportamentos da CID-10 - Descrições clínicas e diretrizes diagnósticas. Porto Alegre: Artes Médicas, 1993.

PATTO, Maria Helena Souza. A Produção do Fracasso Escolar: histórias de submissão e rebeldia. São Paulo: Casa do Psicólogo, 1999.

ROSE, Nikolas. La Politica della Vita. Tradução de Marchetti M. Pipitone G. Ed. Einaudi, Itália, 2007.

SILVA, Ana Paula Ferreira da. Arthur Ramos e a "creança problema" na Escola Pública dos Anos de 1930. Trama Interdisciplinar, São Paulo, v. 2, n. 2, p. 58-73, 2011.

STEPHANOU, Maria. Tratar e Educar: discursos médicos nas primeiras décadas do século XX. 1999. Tese (Doutorado em Educação) - Programa de Pós-graduação em Educação, Universidade Federal do Rio Grande do Sul, Porto Alegre, 1999.

VALDERRAMA, Jorge Márquez. Medicalização da Vida Soropositiva. In: CAPONI, Sandra et al. Medicalização da Vida: ética, saúde pública e indústria farmacêutica. Palhoça: Unisul, 2010. P. 72-88.

ZUCOLOTO, Patrícia Carla Silva do Vale. O Médico Higienista na Escola: as origens históricas da medicalização do fracasso escolar. Revista Brasileira de Crescimento e Desenvolvimento Humano, São Paulo, v. 17, n. 1. p. 135-145, 2007.

Educação \& Realidade, Porto Alegre, v. 40, n. 4, p. 1079-1102, out./dez. 2015.1101 
Ana Carolina Christofari é doutora em Educação pelo PPGEDU/UFRGS na área de Educação Especial e Inclusão Escolar. Integrante do Núcleo de Estudos em Políticas de Inclusão Escolar NEPIE/FACED/UFRGS. Atua como professora da Rede Municipal de Ensino de Porto Alegre desde 2009. A temática da medicalização dos modos de ser e de aprender é discutida na tese da autora.

E-mail: carolc29@gmail.com

Claudia Rodrigues de Freitas é doutora em Educação pelo PPGEDU/UFRGS. Professora da Faculdade de Educação e do Programa de Pós-Graduação da UFRGS. Integrante do Núcleo de Estudos em Políticas de Inclusão Escolar NEPIE/FACED/UFRGS. Pesquisa os processos de Medicalização da vida escolar.

E-mail: freitascrd@gmail.com

Claudio Roberto Baptista é doutor em Educação pela Universidade de Bologna. Professor da Faculdade de Educação e do Programa de Pós-Graduação da UFRGS. Coordena o NEPIE- Núcleo de Estudos em Políticas de Inclusão Escolar da UFRGS. Pesquisa os processos de inclusão escolar e a educação especial.

E-mail: baptistacaronti@yahoo.com.br 